Research Article

\title{
Statistical analysis of fiber quality to obtain a correlation between the fiber and yarn quality
}

\begin{abstract}
The purpose of this research was to make a correlation between the fiber and yarn quality based on different properties of the fiber. The properties of cotton fiber were tested by the High Volume Instrument (HVI) machine. Firstly, we collect fiber from a different lot and then tested the properties by the High Volume Instrument (HVI) Machine. After that, we made yarn from that lot and made the same count of yarn. The tested properties were mic, length, maturity, strength, elongation, moisture, etc. The same count of yarn was tested by the USTER EVENESS TESTER machine. Comparing the HVI report and the USTER TESTER report, we saw that how to effect different fiber properties of the different lot on the same count of yarn quality. Then we made a correlation between them. The observation suggested that yarn strength and fineness are depended upon fiber maturity. This paper reports a glimpse of the effect of fiber properties on yarn quality.
\end{abstract}

Keywords: HVI machine, uster tester 5, lea strength tester, yarn quality, fiber properties
Volume 6 Issue 6 - 2020

\author{
Sheikh Sad Habib-A-Rasul,' Md Arif Saleh \\ Tasin,' Md Abdullah Al Mamun, ${ }^{2}$ Md Fahim \\ Ahmed,' Taosif Ahmed, I Rony Mia' \\ 'Department of Textile Engineering, National Institute of Textile \\ Engineering \& Research (NITER), Bangladesh \\ ${ }^{2}$ School of Textile Science \& Engineering, Wuhan Textile \\ University, China
}

\begin{abstract}
Correspondence: Rony Mia, Research Assistant, College of Chemistry \& Chemical Engineering, Wuhan Textile University, Wuhan 430073, China, Tel +86-15623233835,
\end{abstract}

Emailmroni_mia@niter.edu.bd

Received: October 25, 2020 | Published: November 05, 2020

\section{Introduction}

Textile fiber is the raw material to produce various types of textile finished products. ${ }^{1}$ A fiber that can be spun into yarn or processed into textiles such as woven, knit, lace, felt, non-woven, etc.by utilizing an appropriate interlacing method is called textile fiber. ${ }^{2,3}$ Cotton cultivating country-Australia, China, India, USA, Pakistan, Africa, Nigeria, Uzbekistan, Kazakhstan, Bangladesh, etc. Fiber property varies from country to country. ${ }^{4,5}$ Fiber properties are testing by the HVI machine. ${ }^{6,7}$ HVI means a High Volume Instrument. Yarn is a continuous strand of fiber. It is a substantial length that has a small cross-section with or without the twist. Yarn properties are tested by Uster Tester and Strength Tester. ${ }^{89}$ Yarn quality depends, most nylon fiber quality. ${ }^{10,11}$

\section{Aim of the research}

The research aims to understand the relation between the fiber and yarn quality very well and to study them. This would be beneficial for the productivity of good and qualified yarn. By learning it properly, it can be possible that we use less good fiber and can produce quality full yarn.

\section{Research objectives}

a. To know about the fiber quality.

b. To know about the relation between fiber property and yarn quality.

c. To analyze the various types of report.

d. To analyze the HVI report.

e. To analyze the USTER EVENESS tester report.

f. To analyze the $\mathrm{U} \%, \mathrm{CVm} \%$, imperfection, hairiness.

g. To analyze the IPI value of report.

h. To learn how to do project work \& make report.

\section{Literature review}

Yarn quality depends on fiber properties, the testing of fibers was always of importance to the spinner. It is done by the HVI machine.
High volume instrument systems are based on the fiber bundle strength testing, i.e. many fibers are checked at the same time and their average values are determined. Traditional testing using micronaire, pressley, stelometre, and fibro graph is designed to determine the average value for a large number of fibers, the so-called fiber bundle tests. ${ }^{12,13}$ In HVI, the bundle testing method is automated. Here, the time for testing is less and so the number of samples that could be processed is increased, quite considerably. The influence of the operator is reduced. ${ }^{14,15}$ Following properties of the fiber are testing HVI machine:
i. Micronaire (mic)
ii. Upper half mean length (Len)
iii. Uniformity index (Unf)
iv. Short fiber index (SFI)
v. Strength (Str)
vi. Elongation (Elg)
vii. Moisture (moist)
viii. Reflectence (Rd)
ix. Yellowness $(+b)$
X. Color grade (C Grade)
xi. Trush count ( $\operatorname{Tr}$ count)
xii. Trush Area ( $\operatorname{Tr}$ area)
xiii. Trush Grade (Tr Grade)
xiv. Neps (Nep)
xv. Spinning consistency index (SCI)

\section{Methodology}

We had continued our thesis step by step. We have taken decision that we will continue our thesis through the following steps:

a. We collected fibers from different lots of same or different countries.

b. We had tested the fibers with HVI machine 
c. We had selected at least three properties from HVI properties.

d. We had produced same count yarn from different lots.

e. We had tested those yarn properties by the Evenness tester, lea strength tester etc.

It will be recorded every step and its results on Microsoft words and statically data may would be record Microsoft excel.

\section{Material \& equipment}

Material: $100 \%$ cotton (Indian) is used for this experiment.

Equipment: The following equipment's are used to complete this experiment:
i. USTER AFIS Pro
ii. USTER HVI Spectrogram
iii. USTER Tester 5
iv. Lea strength tester

\section{Research limitations}

During this research, at first, we wanted to call fixed value mic, length, strength, naps. But it is quite impossible because in every laydown or in a bale there is various fiber with different parameters, but they are nearly similar and they always use an average value of mic, naps, length, strength. We were also done that. Another limitation is the shortage of proper lab facilities. We were internship students. We didn't have proper access to the lab and testing machinery. Our research duration was the entire final year, but originally, we have done it within only one month. Because on our campus we were not provided with the necessary types of machinery and the components. In our internship period, we had only 9 days for our Qc department and that was only the time we got for our research. Though there were limitations we had given our best effort to complete our research.

\section{Result and discussion}

\section{Relation between micronaire and count strength product}

This graph shows a state line which is created by relation between CSP value and MIC value. By this graph we see that if MIC value is increasing the CSP value is decrease (Figure 1).

\begin{tabular}{llll}
\hline MIC value & 4.6 & 4.72 & 4.84 \\
CSP value & 2607 & 2588 & 2570 \\
\hline
\end{tabular}

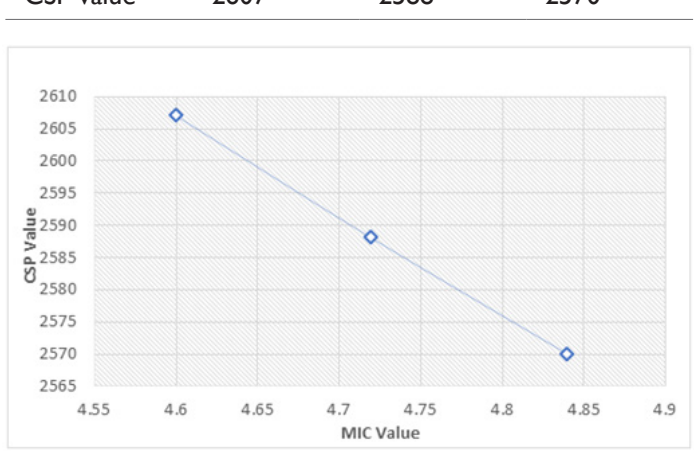

Figure I Relation between micronaire and count strength product in line graph.

\section{Relation between naps in fiber and naps in yarn}

The graph shows a state line which is created by relation between naps in fiber and naps in yarn. By this graph we see that if naps in fiber are high the naps in yarn are high (Figure 2).

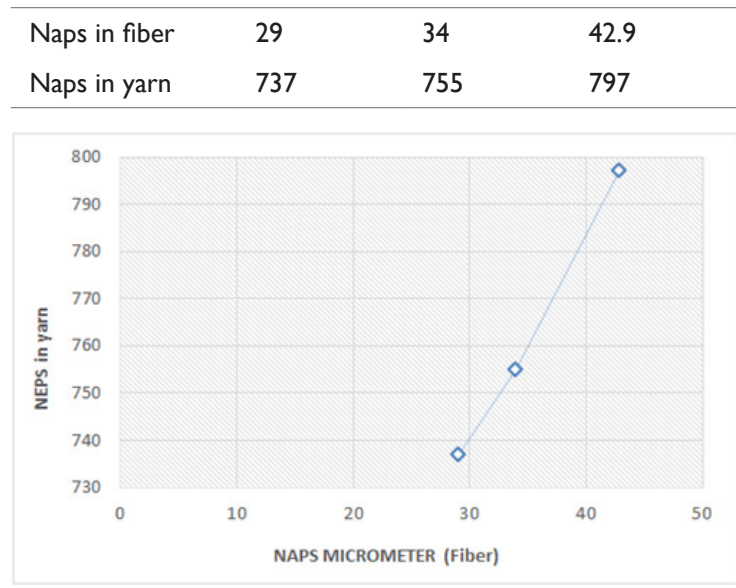

Figure 2 Relation between naps in fiber and naps in yarn in line graph.

\section{Relation between fiber length and imperfection index}

By this graph we see that if fiber length is high the imperfection index is high (Figure 3).

\begin{tabular}{llll}
\hline Fiber length & 25.2 & 28.6 & 29.25 \\
Imperfection index & 64.4 & 76.22 & 80 \\
\hline
\end{tabular}

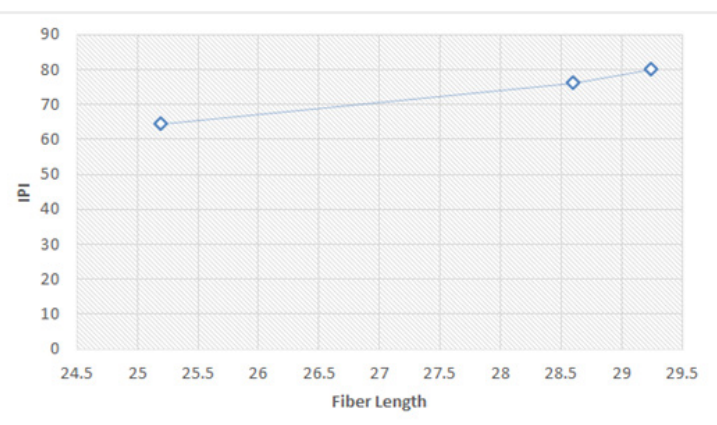

Figure 3 Relation between fiber length and imperfection index in line graph.

\section{Relation between length of fiber and hairiness of yarn}

By this graph we see that if the fiber length is high the hairiness is high (Figure 4).

\begin{tabular}{llll}
\hline Length of fiber & 25.2 & 28.6 & 29.25 \\
Hairiness in yarn & 4.86 & 4.74 & 4.71 \\
\hline
\end{tabular}

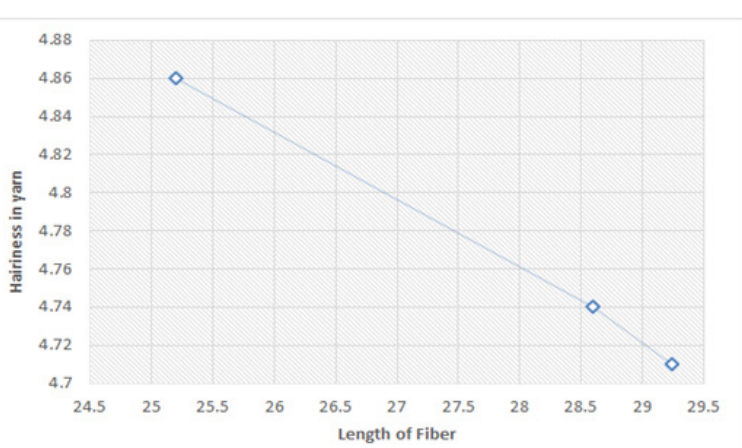

Figure 4 Relation between length of fiber and hairiness of yarn in line graph. 


\section{Relation between maturity of fiber and co efficient variation of yarn}

By this graph we see that if maturity is high the co efficient variation of yarn is low (Figure 5).

\begin{tabular}{llll} 
Maturity of fiber & 0.89 & 0.9 & 0.91 \\
CV of yarn & 15.03 & 13.2 & 12.31 \\
\hline
\end{tabular}

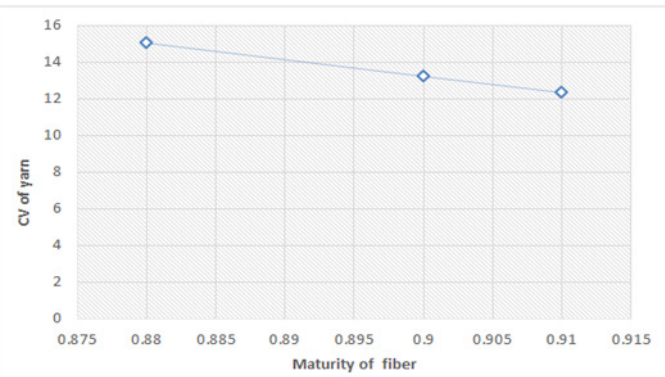

Figure 5 Relation between maturity of fiber and co efficient variation of yarn graph.

in line graph.

\section{Relation between maturity of fiber and neps per kilometer}

By this graph we see that maturity of fiber is increase the neps in yarn is decrease (Figure 6).

\begin{tabular}{llll} 
Maturity of fiber & 0.89 & 0.9 & 0.91 \\
Neps per km & 42.9 & 35.6 & 29 \\
\hline
\end{tabular}

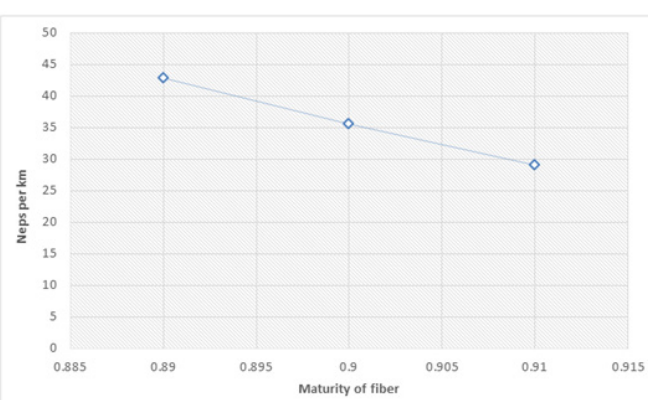

Figure 6 Relation between maturity of fiber and neps per kilometer in line graph.

Relation between elongation of fiber and count strength product

By this graph we see that if elongation of fiber is increasing the CSP is increase (Figure 7).

\begin{tabular}{llll}
\hline Elongation of fiber & 4.02 & 4.4 & 5.2 \\
Count strength product & 2588 & 2607 & 2610 \\
\hline
\end{tabular}

\begin{tabular}{r|rrr}
2615 \\
2610 \\
2605 \\
2595 \\
2590 \\
2585 \\
0
\end{tabular}

Figure 7 Relation between elongation of fiber and count strength product in line graph.

\section{Relation between short fiber contain and imperfection index}

By this graph we see that if short fiber content increase then imperfection index increases (Figure 8).

\begin{tabular}{llll}
\hline Short fiber contains & 5.7 & 6.91 & 8.6 \\
Imperfection index & 64.4 & 72.22 & 80 \\
\hline
\end{tabular}

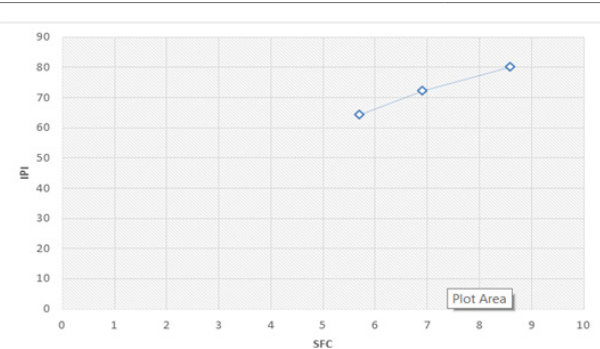

Figure 8 Relation between short fiber contain and imperfection index in line

Relation between short fiber contain and hairiness of yarn

By this graph we see that if short fiber content increase then hairiness also increases (Figure 9).

\begin{tabular}{llll}
\hline Short fiber contains & 5.7 & 6.4 & 7.2 \\
Hairiness of yarn & 4.56 & 4.63 & 4.86
\end{tabular}

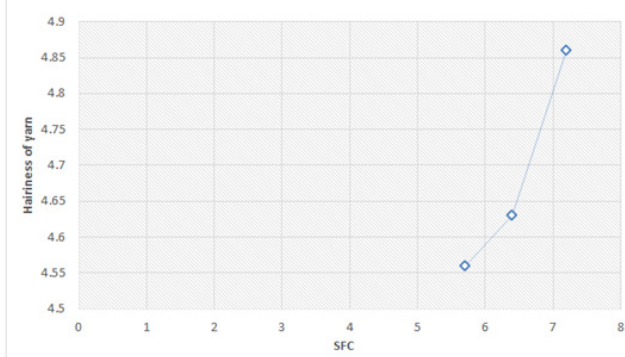

Figure 9 Relation between short fiber contain and hairiness of yarn in line graph.

\section{Relation between fiber strength and count strength product}

By this graph we see that if fiber strength increases then CSP increases (Figure 10).

\begin{tabular}{llll}
\hline Fiber strength & 28.77 & 29.54 & 32.8 \\
Count strength product & 2570 & 2588 & 2607 \\
\hline
\end{tabular}

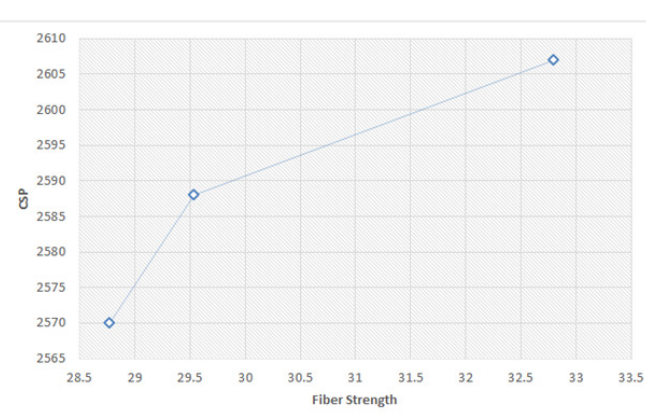

Figure I0 Relation between fiber strength and count strength product in line graph. 


\section{Conclusion}

This project works about the effect of fiber properties on yarn quality. For this project, we collect the HVI value of fiber such as Mic, length, strength, maturity, naps, SCI, SFI, elongation, $+b, \mathrm{Rd}$, etc. We also collected USTER tester 5 reports of yarn. Such as U\%, CV\%, Thick, Thin, Naps, etc. According to these two reports, we try to find out the relation between fiber properties and yarn quality. We think that this research is going to be helpful for good productivity of quality full yarn from less qualified fibers and further research can bring a significant development in the spinning process.

\section{Acknowledgments}

None.

\section{Funding}

None.

\section{Conflicts of interest}

There is no conflict of interest in publishing articles according to the author's declaration.

\section{References}

1. Houck MM. Identification of textile fibers. Elsevier; 2009.

2. Lee SC, Prosky L. International survey on dietary fiber: definition, analysis, and reference materials. Journal of AOAC International. 1995;78(1):22-36.

3. Ozturk E, Karaboyacı M, Yetis U, et al. Evaluation of integrated pollution prevention control in a textile fiber production and dyeing mill. Journal of cleaner production. 2015;88:116-124.

4. A Al-Nasser, M Al-Talib. The ranked sample-mean Monte Carlo method for unidimensional integral estimation. Asian Journal of Mathematics \& Statistics. 2010;3:130-138.
5. Baidya K, Taosif A, Rony M, et al. Study on yarn quality variation from spinning position to position in ring frame. 2020:18-25.

6. Suh M, Sasser P. The technological and economic impact of high volume instrument (HVI) systems on the cotton and cotton textile industries. Journal of the Textile Institute. 1996;87(3):43-59.

7. Illarionova K, Grigoryev S, Asfondiarova I. HVI in implementation of internet technologies for providing quality of textile articles. IOP Conference Series: Materials Science and Engineering. 2019;497(1):012110.

8. Azzam HA, Mohamed ST. Adapting and tuning quality management in spinning industry. Autex Research Journal. 2005;5(4):246-258.

9. Rahman MM, Anamul Haqueet TM, Sourav NS, et al. Synthesis and investigation of dyeing properties of 8-hydroxyquinoline-based azo dyes. Journal of the Iranian Chemical Society. 2020:1-10.

10. MacGregor R, Macarak EJ, Kefalides NA, et al. Comparative adherence of granulocytes to endothelial monolayers and nylon fiber. The Journal of Clinical Investigation. 1978;61(3):697-702.

11. Mackeen PC, Person S, Warner SC, et al. Silver-coated nylon fiber as an antibacterial agent. Antimicrobial agents and chemotherapy. 1987;31(1):93-99.

12. Mia R, Islam MA, Ahmed B, et al. Woolenization of jute fibre. 2017;13(30):314.

13. Majumdar A, Majumdar PK, Sarkar B. Application of an adaptive neurofuzzy system for the prediction of cotton yarn strength from HVI fibre properties. Journal of the Textile Institute. 2005;96(1):55-60.

14. Üreyen ME, Kadoglu H. Regressional estimation of ring cotton yarn properties from HVI fiber properties. Textile Research Journal. 2006;76(5):360-366.

15. Byler R, Anthony W, Mangialardi G. Improving the HVI strength measurement by adjusting for measured moisture content. Applied Engineering in Agriculture. 2001;17(6):821. 